\title{
NMR Studies on Dynamics of Water Intercalated in Clay Minerals
}

\author{
Shin'ichi Ishimaru and Ryuichi Ikeda \\ Department of Chemistry, University of Tsukuba, Tsukuba 305-8571, Japan \\ Reprint requests to Dr. S. I.; Fax: 81-298-53-6503, E-mail: ishimaru@staff.chem.tsukuba.ac.jp
}

Z. Naturforsch. 54 a, 431-436 (1999); received April 12, 1999

\begin{abstract}
The dynamics of water molecules intercalated in $\mathrm{D}_{2} \mathrm{O}$ saturated synthetic and natural smectites, and a synthetic Na-fluormica were studied by measurements of solid state ${ }^{2} \mathrm{H}$ NMR spectra and spin-lattice relaxation times at $150-370 \mathrm{~K}$. The obtained results could be explained by the 2-site flip, the $C_{2}$ rotation and the isotropic rotation of the $\mathrm{D}_{2} \mathrm{O}$ molecules in smectites. In fluormica, the isotropic motion was undetectable, but the axial rotation of the hydration sphere as a whole was observed. The activation energies and correlation times of the $C_{2}$ rotation were almost independent of the interlayer cations but depended on the character of clay-layers.
\end{abstract}

Key words: Clay Minerals; NMR; Intercalated Water; $T_{1}$.

\section{Introduction}

Layer-structured clay minerals have been characterised by their large adsorption capacity in the interlayer space and by the fact that their adsorption character can be modified by the charge density of clay layer and interlayer cations. Since molecules adsorbed in the two-dimensional space are expected to behave differently from those in the bulk state, their dynamic properties have extensively been studied. As a typical adsorbent, the structure and dynamics of water in clay minerals have been investigated by various methods [1, 2], e.g., measurements of thermodynamic parameters [3 - 5], neutron diffraction [6], quasielastic neutron scattering (QENS) [7 - 9] and NMR [10 - 15], and simulations of force field [16], Monte Carlo (MC) [17] and molecular dynamics (MD) [18].

In highly charged clays, such as Na-vermiculite, adsorbed water molecules form an octahedral hydration shell around a cation [16]. In the case of low charged clays, such as montmorillonite, however, adsorbed water molecules can be located not only around the cations but in the interstitial space. This complicated water-environment makes the analysis of the experimental data difficult, and this problem is also caused by the disordered structure in clay minerals, such as inhomogeneity of the charge distribution, stacking defaults in the layers, and considerable effects from surface edges resulting from fine sizes.
Previously we reported ${ }^{2} \mathrm{H}$ and ${ }^{7} \mathrm{Li}$ NMR studies on $\mathrm{D}_{2} \mathrm{O}$ saturated synthetic Li-saponite and discussed $\mathrm{D}_{2} \mathrm{O}$ motions and the local structure around cations over a wide temperature range [19]. In this study, we perform measurements of ${ }^{2} \mathrm{H}$ NMR spectra and spin-lattice relaxation times $\left(T_{1}\right)$ of six kinds of $\mathrm{D}_{2} \mathrm{O}$ saturated clay minerals and attempt to reveal effects of cations and clay-layer on dynamics of adsorbed water molecules.

We selected the following synthetic clays for NMR measurements to avoid the influence from paramagnetic impurities: Na-fluormica, Na-hectorite, Nasaponite, Cs-saponite and tetramethylammonium(TMA)-saponite. A natural clay, Tsukinuno Na-montmorillonite containing 19,300 ppm Fe, was also used for comparison.

\section{Experimental}

Synthetic Na-saponite $\left(\mathrm{Na}_{0.4} \mathrm{Si}_{3.6} \mathrm{Al}_{0.4} \mathrm{Mg}_{3}(\mathrm{OH})_{2}\right.$ $\mathrm{O}_{10}$ ) being a reference clay (JCSS-3501) of the Clay Science Society of Japan (CSSJ), synthesized by Kunimine Industries Co., Ltd was obtained from CSSJ. The synthetic clays $\mathrm{Na}$-hectorite $\left(\mathrm{Na}_{0.4} \mathrm{Si}_{4} \mathrm{Mg}_{3.1} \mathrm{Li}_{0.3}\right.$ $\left.(\mathrm{OH})_{2} \mathrm{O}_{10}\right)$ and Na-tetrasilicicfluormica $\left(\mathrm{Na}_{0.75} \mathrm{Si}_{4}-\right.$ $\left.\mathrm{Mg}_{2.7} \mathrm{~F}_{0.85}(\mathrm{OH})_{1.2} \mathrm{O}_{10}\right)$ were kindly gifted from $\mathrm{CO}-$ OP Chemical Co., Ltd. A natural Yamagata Tsukinuno montmorillonite $\left(\mathrm{Na}_{0.3} \mathrm{Si}_{4} \mathrm{Al}_{1.7} \mathrm{Mg}_{0.3}(\mathrm{OH})_{2} \mathrm{O}_{10}\right)$ was given by Kunimine Industries Co., Ltd.

Cs and TMA-saponites were prepared by the standard cation exchange method from Na-saponite using 
a $2 \mathrm{~mol} \mathrm{dm}^{-3} \mathrm{CsCl}$ and a TMACl aqueous solution, respectively. The suspensions of the cation exchanged clays were filtered and washed with distilled water until the filtrates showed negative reaction to the $\mathrm{AgNO}_{3}$ test.

The specimens for NMR measurements were put in glass tubes and aspirated at room temperature for one day, then exposed to $\mathrm{D}_{2} \mathrm{O}$ vapour at its saturated vapour pressure at room temperature. These specimens were then sealed with helium gas of atmospheric pressure. The $\mathrm{D}_{2} \mathrm{O}$ contents in these specimens were determined by the weight loss after heating to $200^{\circ} \mathrm{C}$.

The ${ }^{2} \mathrm{H}$ NMR spectra and $T_{1}$ were measured with a Bruker MSL-300 NMR system at $150-370 \mathrm{~K}$. The temperature was controlled within $\pm 5 \mathrm{~K}$. The evaluated error in the $T_{1}$ measurement was $\pm 10 \%$.

\section{Results and Discussion}

\section{X-Ray Diffraction and Gravimetric Analysis}

The X-ray diffraction of powdered smectites showed diffused patterns, while Na-fluormica gave sharp peaks. The determined $d(001)$ spacings and $\mathrm{D}_{2} \mathrm{O}$ contents per cation of each clay are listed in Table 1 . The $\mathrm{D}_{2} \mathrm{O}$ contents determined in alkali metal clays, except for Na-fluormica, were large compared with the accepted hydration numbers of $\leq 6 \sim 10$ for the cations in aqueous solution [20], and 6 for vermiculite [13], implying the existence of non-hydrated water molecules in the interstitial space of the clay layers. On the other hand, $14 \mathrm{D}_{2} \mathrm{O}$ molecules per TMA cation is considered to be not many for a large cation, suggesting that the $\mathrm{D}_{2} \mathrm{O}$ molecules are in the first hydration sphere, although the interaction between the TMA cation and water molecules is so weak that it is difficult to specify the hydration number. Na-fluormica, known as a highly charged mineral with few interstitial sites, showed a small number, 6.7, corre-

Table 1. $\mathrm{D}_{2} \mathrm{O}$ contents and $\mathrm{X}$-ray $d(001)$ spacings in $\mathrm{D}_{2} \mathrm{O}$ saturated clays.

\begin{tabular}{lcc}
\hline Clay & $\mathrm{D}_{2} \mathrm{O}$ molecules / cation $d(001)$ spacing / nm \\
\hline Na-saponite & $15.8 \pm 0.2$ & $1.38 \pm 0.1$ \\
Cs-saponite & $26.0 \pm 0.2$ & $1.37 \pm 0.1$ \\
TMA-saponite & $14.0 \pm 0.2$ & $1.56 \pm 0.1$ \\
Na-hectorite & $14.9 \pm 0.2$ & $1.42 \pm 0.1$ \\
Na-montmorillonite & $19.4 \pm 0.2$ & $1.50 \pm 0.1$ \\
Na-fluormica & $6.7 \pm 0.1$ & $1.24 \pm 0.02$ \\
\hline
\end{tabular}
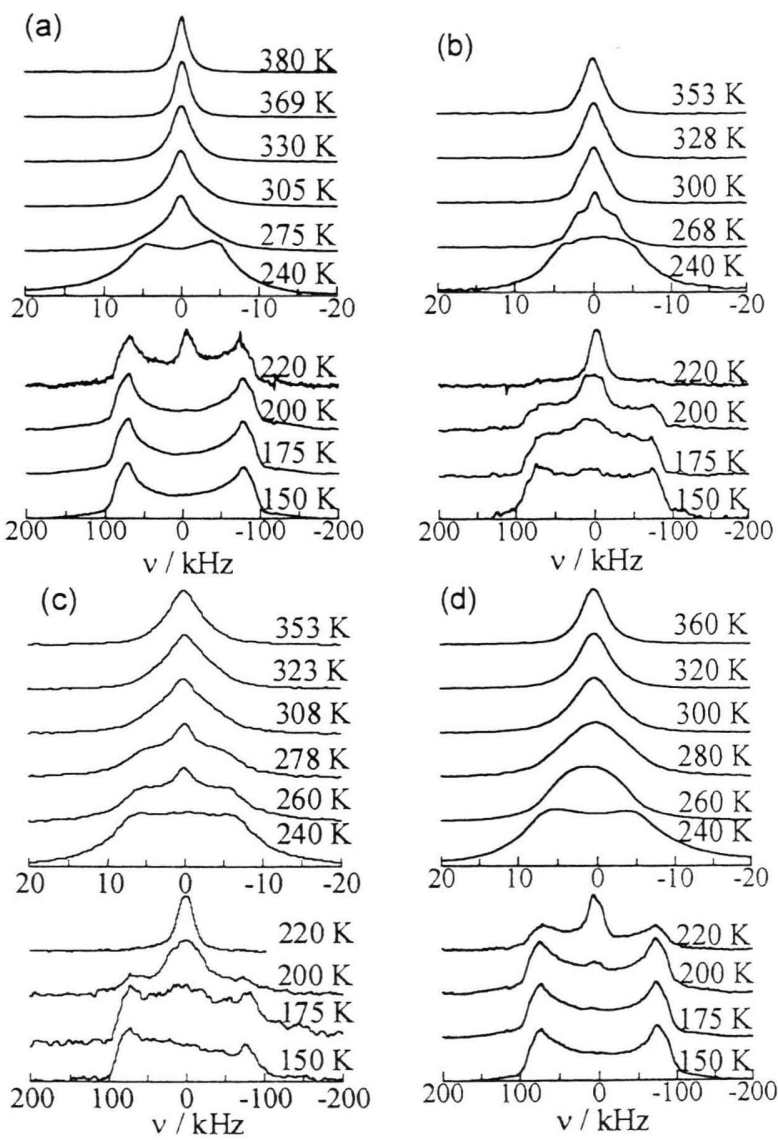

Fig. 1. Temperature dependences of ${ }^{2} \mathrm{H}$ NMR spectra in $\mathrm{D}_{2} \mathrm{O}$ saturated Na-saponite (a), Cs-saponite (b), TMAsaponite (c), and Na-hectorite (d).

sponding to the normal hydration number of 6 for an $\mathrm{Na}^{+}$cation.

\section{${ }^{2}$ H NMR Spectra}

Temperature dependences of the ${ }^{2} \mathrm{H}$ NMR spectra in cation replaced saponites and Na-hectorite are shown in Figure 1. Their common behaviour can be roughly summarized as follows: Estimated quadrupole coupling constants $\left(e^{2} Q q / h\right)$ of $c a$. $220 \mathrm{kHz}$ observed in each sample at $150 \mathrm{~K}$ agree with $220 \mathrm{kHz}$ for the rigid water determined in Lisaponite [19]. Upon heating, a sharp component appeared at the centre of each spectrum at $200-220 \mathrm{~K}$, then, on heating to $240 \mathrm{~K}$, the spectra became a single central absorption line of a doublet structure with a width of $c a$. $20 \mathrm{kHz}$, assignable to $\mathrm{D}_{2} \mathrm{O}$ molecules rotating about their $C_{2}$ axis [13]. Above $300 \mathrm{~K}$, each 


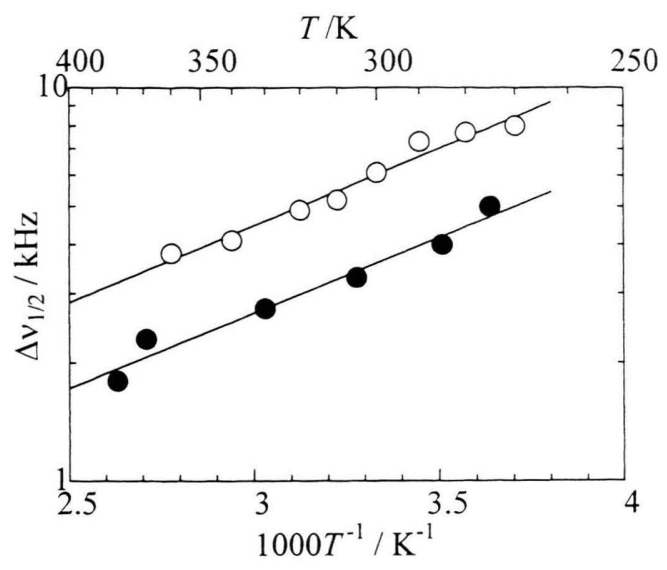

Fig. 2. Temperature dependences of ${ }^{2} \mathrm{H}$ NMR line-widths $\left(\Delta \nu_{1 / 2}\right)$ in $\mathrm{D}_{2} \mathrm{O}$ saturated Na-saponite $(\bullet)$ and Na-hectorite (०) observed above $270 \mathrm{~K}$. Sold lines are best fitted Arrhenius relations.

clay showed a structureless sharp peak corresponding to isotropically rotating $\mathrm{D}_{2} \mathrm{O}$ molecules.

On detailed observations, the spectrum changes in Na-saponite and $\mathrm{Na}$-hectorite, resembling each other, differ somewhat from those in Cs and TMAsaponites. The two Na-clays showed well defined rigid spectra up to $200 \mathrm{~K}$, whereas the central peak already appeared at $175 \mathrm{~K}$ in the latter two clays, implying that the water molecules are more tightly bounded in the Na-clays at low temperatures.

The structure of the central line almost disappeared around $300 \mathrm{~K}$ in the Na-saponite, hectorite, and Cssaponite spectra, but it remained a little even at $323 \mathrm{~K}$ in TMA-saponite. The sharp central ${ }^{2} \mathrm{H}$ line observed at high temperatures indicates that the environment of a hydrogen atom becomes isotropic in the NMR time scale if it jumps among the four tetrahedral sites, because water molecules have tetrahedral symmetry on average in the bulk liquid. As mentioned above, the $\mathrm{D}_{2} \mathrm{O}$ contents in Na- and Cs-smectites (Table 1) are sufficiently high compared with the coordination number of each cation, while this is not the case in the TMA-saponite. These facts suggest that the water molecules make hydrogen-bond networks in Naand Cs-smectites as in bulk-water but form isolated hydration spheres in TMA-saponite.

Finally, the line-width of the structureless peak observed in Na-saponite and hectorite was found to be temperature dependent above $270 \mathrm{~K}$ (Figure 2). This reduction of the line-width can be attributed to the averaging of the electric field gradient (EFG) by

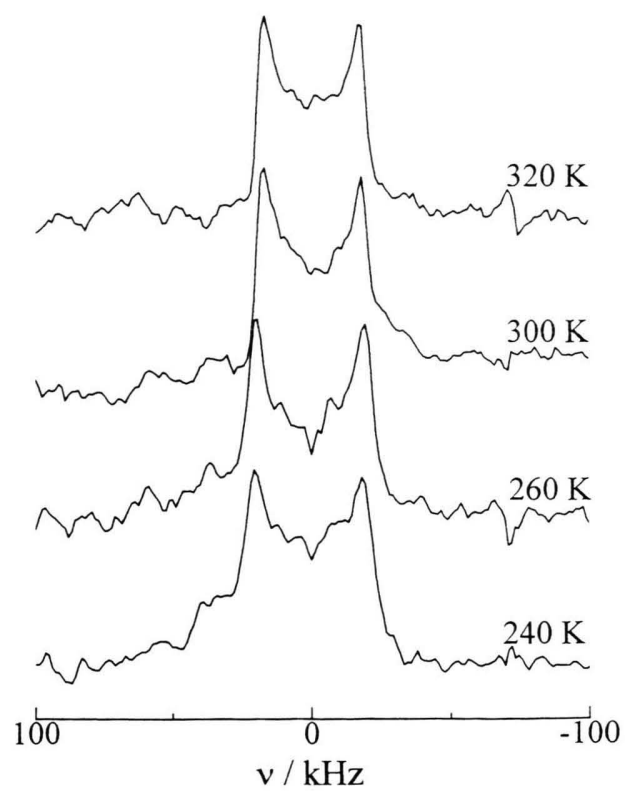

Fig. 3. A temperature dependence of the ${ }^{2} \mathrm{H}$ NMR spectrum in $\mathrm{D}_{2} \mathrm{O}$ saturated Na-fluormica.

the diffusional motion of the $\mathrm{D}_{2} \mathrm{O}$ molecules such as the exchange between hydrate and free molecules. The similar slope of the temperature dependences of the line-width obtained in Na-saponite and hectorite shown in Fig. 2 suggests that this motion has the same activation energy in these two clays.

Cs-Saponite did not show such a reduction in linewidth at high temperatures. We can propose two possible mechanisms for this observation; 1 . the large Csion produces a small EFG at hydrate $\mathrm{D}_{2} \mathrm{O}$ molecules and 2. the cationic diffusion rate is already fast enough to average out the residual EFG in this temperature region because of the low activation energy of water-exchange caused by the negative hydration effect [21].

As shown in Fig. 3, temperature-independent ${ }^{2} \mathrm{H}$ NMR spectra were observed in Na-fluormica above $260 \mathrm{~K}$. The obtained $e^{2} Q q / h=60 \pm 2 \mathrm{kHz}$ and asymmetric parameter $\eta \simeq 0$ are explainable by the rotation of $\mathrm{D}_{2} \mathrm{O}$ molecule about an axis, tilted by $61^{\circ}$ from the molecular $C_{2}$ axis accompanied by a $180^{\circ}$ flip around the $C_{2}$ axis. This angle $61^{\circ}$ agrees well with $65^{\circ}$ [13] reported for the angle between the $C_{3}$ axis of the octahedral hydration shell around the $\mathrm{Na}^{+}$ and the $C_{2}$ axis of water molecules in Na-vermiculite.

${ }^{2} \mathrm{H}$ NMR spectra were also measured in natural $\mathrm{Na}$-montmorillonite but cannot be interpreted because 


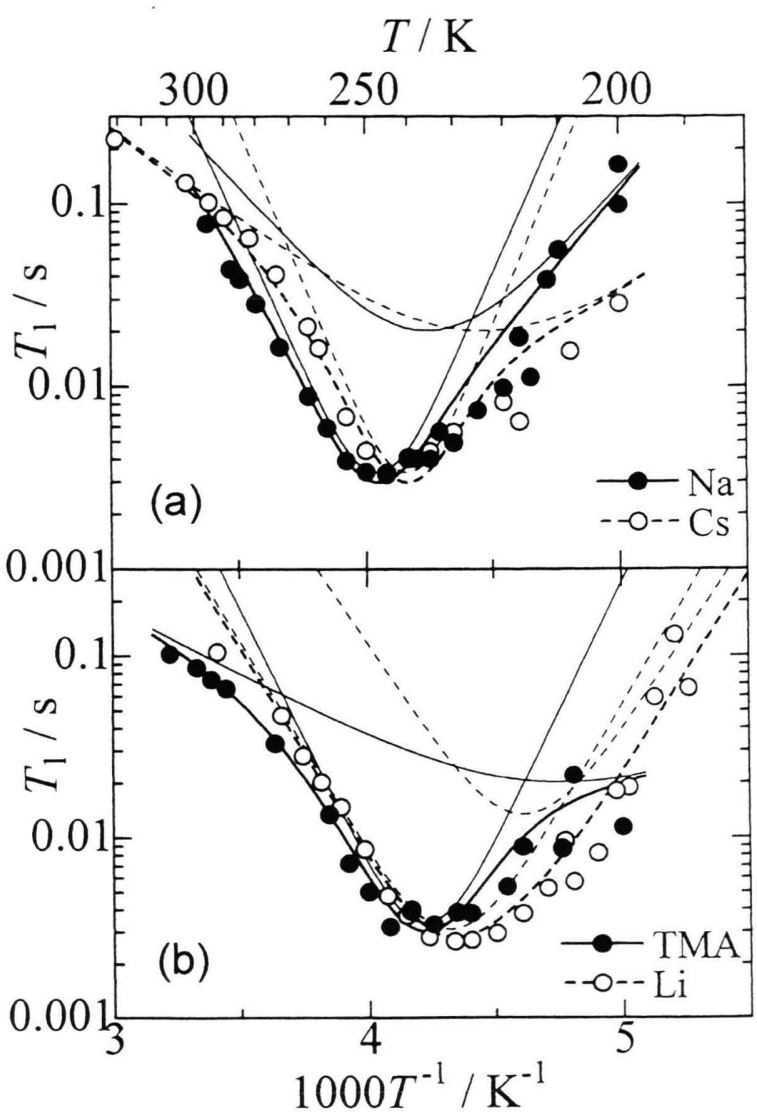

Fig. 4. Temperature dependences of ${ }^{2} \mathrm{H}$ NMR spin-lattice relaxation times $\left(T_{1}\right)$ in $\mathrm{D}_{2} \mathrm{O}$ saturated $\mathrm{Na}-(\bullet)$ and Cs$(\triangle)(a)$ and TMA- $(\times)$ saponites and previously reported Li-saponite (o) (b). Bold lines represent the best-fitted calculated values for $\left(T_{1}\right)_{\text {net }}$, and thin lines for $\left(T_{1}\right)_{\text {mode } 1}$ and $\left(T_{1}\right)_{\text {mode } 2}$.

the spectra were highly deformed probably owing to paramagnetic impurities such as $\mathrm{Fe}^{2+}$ and $\mathrm{Fe}^{3+}$.

\section{${ }^{2}$ H NMR Relaxation Time}

Figures 4 and 5 are the cation and host clay dependences, respectively, of the ${ }^{2} \mathrm{H}$ NMR $T_{1}$. Each specimen showed a $T_{1}$ minimum at $230-240 \mathrm{~K}$. The slopes of the temperature dependences were asymmetric above and below the minimum.

The observed relaxation rate $T_{1}^{-1}$ could be reproduced by adding contributions from two motional modes $\mathbf{1}$ and $\mathbf{2}$ for deep and shallow minima, respectively:

$$
\left(T_{1}\right)_{\text {net }}^{-1}=\left(T_{1}\right)_{\text {mode } 1}^{-1}+\left(T_{1}\right)_{\text {mode } 2}^{-1} .
$$

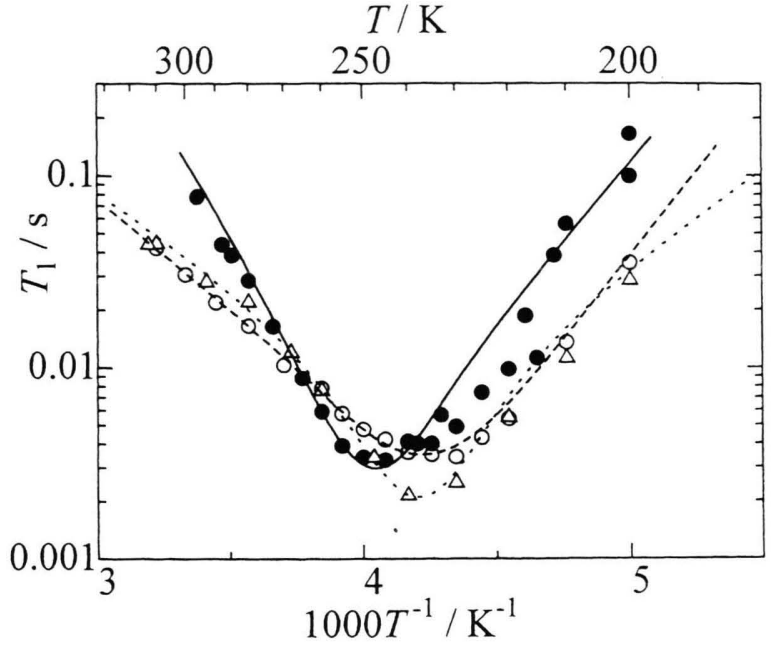

Fig. 5. Temperature dependences of ${ }^{2} \mathrm{H}$ NMR spin-lattice relaxation times $\left(T_{1}\right)$ in $\mathrm{D}_{2} \mathrm{O}$ saturated $\mathrm{Na}$-saponite $(\bullet)$, hectorite (o) and Tsukinuno montmorillonite $(\Delta)$. The bestfitted $\left(T_{1}\right)_{\text {net }}$ are given by - for Na-saponite, - - - for hectorite, and $\cdots$ for montmorillonite.

The $T_{1}^{-1}$ for each mode is represented by a BPP-type equation [22]:

$$
T_{1}^{-1}=C\left[\frac{\tau}{1+\omega^{2} \tau^{2}}+\frac{4 \tau}{1+4 \omega^{2} \tau^{2}}\right]
$$

as an ordinary thermal relaxation, where $C$ is the parameter determined by the reduction of the quadrupole coupling constant, $\Delta e^{2} Q q / h$, by the excitation of the motion, $\omega$ is the ${ }^{2} \mathrm{H}$ Larmor frequency, and $\tau$ is the correlation time of the motion given by the Arrhenius equation

$$
\tau=\tau_{0} \exp \left(E_{\mathrm{a}} / R T\right),
$$

where $E_{\mathrm{a}}$ is the activation energy of the motion.

Table 2. Motional constants $(C)$ and activation energies $\left(E_{\mathrm{a}}\right)$ for the modes $\mathbf{1}$ and $\mathbf{2}$ in $\mathrm{D}_{2} \mathrm{O}$ molecules derived from observed ${ }^{2} \mathrm{H}$ NMR $T_{1}$ data.

\begin{tabular}{lcccc}
\hline \multirow{2}{*}{ Clay } & \multicolumn{2}{c}{$C / 10^{10} \mathrm{~s}^{-2}$} & \multicolumn{2}{c}{$E_{\mathrm{a}} / \mathrm{kJ} \mathrm{mol}^{-1}$} \\
& mode 1 & mode 2 & mode $\mathbf{1}$ & mode 2 \\
\hline Na-saponite & $6.0 \pm 0.6$ & $1.0 \pm 0.2$ & $60 \pm 3$ & $29 \pm 3$ \\
Cs-saponite & $6.0 \pm 0.6$ & $1.0 \pm 0.2$ & $65 \pm 3$ & $19 \pm 2$ \\
TMA-saponite & $6.0 \pm 0.6$ & $1.0 \pm 0.2$ & $55 \pm 3$ & $14 \pm 1$ \\
Li-saponite & $6.5 \pm 0.6$ & $1.5 \pm 0.3$ & $45 \pm 2$ & $40 \pm 3$ \\
Na-hectorite & $5.5 \pm 0.5$ & $0.5 \pm 0.1$ & $35 \pm 2$ & $20 \pm 2$ \\
Na-montmorillonite & $8.0 \pm 0.8$ & $1.7 \pm 0.3$ & $60 \pm 3$ & $19 \pm 2$ \\
\hline
\end{tabular}

* Re-fitted values for previously reported $T_{1}$ data [19]. 
Equations (1) - (3) were fitted to $T_{1}$ data in Figs. 4 and 5 . The best-fitted parameters for each specimen are listed in Table 2. Re-fitted parameters for Li-saponite, whose $T_{1}$ was previously fitted by a single motion [19], are also listed together.

Asymmetric $T_{1}$ curves observed in the present systems have often been analysed by introducing models of $\tau$-distribution $[14,15]$ as reported in complex systems such as glasses, polymers and intercalation compounds. We also tried to apply several models of this type, but obtained unsuccessful results: The observed $T_{1}$ minima, which markedly depend on the degree of $\tau$-distribution, are almost equal except for Na-montmollironite, despite the different degrees of asymmetry in $T_{1}$ curves. The other reason is that $\Delta e^{2} Q q / h$ of $300-330 \mathrm{kHz}$, derived from $T_{1}$ minimum values in Cs- and TMA-saponite using the $\tau$-distribution model, is unacceptably large to be attributed to $\mathrm{D}_{2} \mathrm{O}$ motions, which give at most $230 \mathrm{kHz}[23,24]$ even for the rigid water molecules rotating isotropically.

As for mode 1, the $C$ values coincided within experimental errors except for Na-montmorillonite, suggesting that we observed the same motion in these clays. From the determined $C$ values, neglecting the contribution from $\eta$, the $\Delta e^{2} Q q / h$ caused by the motion was estimated to be $200 \pm 20 \mathrm{kHz}$ [19]. The larger $C$ value in Na-montmollironite than in the other diamagnetic systems is explainable by the contribution from dipole-dipole interactions between ${ }^{2} \mathrm{H} \mathrm{nu}$ clei and unpaired electrons. On the other hand, it is difficult to attribute the $C$ values for mode 2 to the same motion because they have much ambiguity and disperse in a range of $0.5-1.5 \times 10^{10} \mathrm{~s}^{2}$.

Around the $T_{1}$ minimum, the $\tau$ of the concerning motion becomes nearly equal to the ${ }^{2} \mathrm{H}$ Larmor frequency, while the same motion affects the NMR line-shape at the temperature where $\tau$ approaches the line-width, i.e., $10 \sim 100 \mathrm{kHz}$. We can, accordingly, estimate the temperature where the spectral change is observed, provided the $T_{1}$ minimum temperature

[1] Chemistry of Clays and Clay Minerals, ed. by A. C. D. Newman, Wiley, New York 1987; Mineral. Soc. of Great Britain Monograph, No. 6.

[2] Advanced Chemical Method of Soil and Clay Minerals Research, ed. by J. W. Stucki and W. L. Banwart, D. Reidel Publishing Co., London 1980.

[3] P. F. Low, Soil. Sci. Soc. Amer. J. 43, 651 (1979). and the activation energy are obtained. Applying this procedure, the spectral changes at $c a .200 \mathrm{~K}$ can be connected with mode 1 in all clays. Thus we can assign mode 1 to the $C_{2}$ rotation of $\mathrm{D}_{2} \mathrm{O}$ molecules because, as shown in Fig. 1, a reduction of the linewidth attributed to the $C_{2}$ rotation was recognized around $220 \mathrm{~K}$. Analogous narrowings for mode 2 are expected below $150 \mathrm{~K}$ in Cs- and TMA-saponites, and near $180 \mathrm{~K}$ in Na-saponite and hectorite. A central component explainable by a large $\eta$ was observed at $150-200 \mathrm{~K}$ in the former two clays. This spectral change can be assigned to the 2-site flipping motion. On the other hand, any evident spectral change was absent in the latter two clays below $200 \mathrm{~K}$, probably because the narrowing is overlapped with that of mode 1.

The $E_{\mathrm{a}}$ value of mode 1 seems to be insensitive to the kind of cation but sensitive to the character of the clay-layers. This fact also supports our assignment of mode 1 to the $C_{2}$ rotation which is more susceptible to interactions between $\mathrm{D}_{2} \mathrm{O}$ and the clay surface and/or hydrogen-bonds among $\mathrm{D}_{2} \mathrm{O}$ molecules than to cation-water interaction. The $E_{\mathrm{a}}$ difference in saponites and hectorite can be explained by the position of the anionic centres in the clay-layer: Saponite and hectorite have isomorphic structures, but the anionic centre is placed at the layer surface in saponite, but at the centre of the layer in hectorite. The longer distance between the charge centre and the $\mathrm{D}_{2} \mathrm{O}$ molecules in hectorite is expected to lead the weaker interaction, i.e., the lower $E_{\mathrm{a}}$. In montmorillonite, however, a high $E_{\mathrm{a}}$ of $60 \mathrm{~kJ} \mathrm{~mol}^{-1}$ was obtained although the anionic centres are at the inside of the layer. The fact that the montmorillonite has a bioctahedral layer structure [25] may give rise to the difference in $E_{\mathrm{a}}$ from that of the trioctahedral clays saponite and hectorite.

This work was partly supported by a Grant-inaid for Scientific Research No. (B)0944023 and (C)10640554 from the Ministry of Education, Science, Sports, and Culture, Japan.

[4] P. F. Low and J. F. Margheim, Soil. Sci. Soc. Amer. J. 43, 473 (1979).

[5] P. F. Low, Soil. Sci. Soc. Amer. J. 44, 667 (1980).

[6] D. H. Powell, K. Tongkhao, S. J. Kennedy, and P. G. Slade, Phisica B241, 387 (1998).

[7] D. J. Cebula, R. K. Thomas, and J. W. White, Clays Clay Miner. 29, 241 (1981). 
[8] J. J. Tuck, P. L. Hall, M. H. B. Hayes, D. K. Ross, and C. Poinsignon, J. Chem. Soc., Faraday Trans. 180 , 309 (1984).

[9] J. J. Tuck, P. L. Hall, M. H. B. Hayes, D. K. Ross, and J. B. Hayter, J. Chem. Soc., Faraday Trans. 1 81, 833 (1985).

[10] A. M. Hecht and E. Geissler, J. Colloid Interface Sci. 34, 32 (1970).

[11] D. E. Woessner, B. S. Snowden, Jr., and G. H. Meyer, J. Colloid Interface Sci. 34, 43 (1970).

[12] A. M. Hecht and E. Geissler, J. Colloid Interface Sci. 44, 1 (1973).

[13] J. Hougardy, W. E. E. Stone, and J. J. Fripiat, J. Chem. Phys. 64, 3840 (1976).

[14] J. J. Fripiat, Advanced Chemical Method of Soil and Clay Minerals Research, ed. by J. W. Stucki and W. L. Banwart, D. Reidel Publishing Co., London 1980, pp. 245.

[15] Progress in Intercalation Research, ed. by W. MüllerWarmuth, R. Schöllhorn, Kluwer, Dordrecht 1994.

[16] R. F. Giese and J. J. Fripiat, J. Colloid Interface Sci. 71, 441 (1979).
[17] N. T. Skipper, K. Refson, and J. D. C. McConnell, J. Chem. Phys. 94, 7434 (1991).

[18] K. Refson, N. T. Skipper, and J. D. C. McConnell, Geochemistry of Clay-pore Fluid Interactions, ed. by D. A. C. Manning, P. L. Hall, and C. R. Hughes, Chapman \& Hall, London 1993, pp. 62.

[19] S. Ishimaru and R. Ikeda, Z. Naturforsch. 52a, 863 (1997).

[20] Ionic Solvation, ed. by G. A. Krestov, N. P. Novosyolov, I. S. Perelygin, A. M. Kolker, L. P. Safonova, V. D. Ovchinnikova, and V. N. Trostin, Ellis Horwood, New York 1994, Chapt. 5.

[21] O. Ya. Samoilov, Discuss. Faraday Soc. 24, 141 (1957).

[22] A. Abragam, The Principles of Nuclear Magnetism, Clarendon Press, Oxford 1961.

[23] P. Waldstein, S. W. Rabideau, and J. A. Jackson, J. Chem. Phys. 41, 3407 (1964).

[24] D. Lankhorst, J. Schriever, and J. C. Leyte, Ber. Bunsenges. Phys. Chem. 86, 215 (1982).

[25] X-ray Identification and Crystal Structure of Clay Minerals, ed. by G. Brown, Mineral. Soc. of Great Britain Monograph No. 5, Wiley, New York 1961. 